\title{
The influence of sowing dates on the oil content and fatty acid composition of standard, mid-oleic and high-oleic types of sunflower (Helianthus annuus L.)
}

\author{
Murat Reis AKKAYA ${ }^{1 \star}$, Abdullah ÇİL ${ }^{2}$, Ayşe Nuran ÇİL ${ }^{2}$, Hatice YÜCEL ${ }^{2}$, Osman KOLA ${ }^{1}$
}

\begin{abstract}
This study aimed to determine the oil ratios and fatty acid compositions of sunflowers grown in the warm climate of the Çukurova region at different sowing dates. It was found that the crude fat ratios of standard, mid-oleic and high-oleic sunflower types were $42.57 \%, 39.35 \%$ and $39.07 \%$, respectively. Crude oil ratios of high-oleic and mid-oleic sunflower types were significantly decreased $(\mathrm{p}<0.05)$ at SD4 (sowing date 4, May 30th). The oleic acid contents in standard, mid-oleic and high-oleic sunflower types were found to be $60.08 \%, 74.35 \%$ and $88.1 \%$, respectively. The oleic acid ratios of standard sunflower types were determined to be significantly lower at SD1 (April 15th) ( $\mathrm{p}<0.05)$. The results show that it is more appropriate to sow the sunflowers between SD1 and SD2 (15 April to 30 April) in terms of producing the required oil and oleic acid contents. Also, both oil ratios and fatty acid compositions can change according to the sowing dates.
\end{abstract}

Keywords: sunflower oil; oil acid composition; oleic acid content; sowing date; temperature.

Practical Application: This study attempted to determine the change in oil content and fatty acid composition depending on genotypes and sowing dates, and also the optimum sowing dates for sunflowers cultivated in the Eastern Mediterranean region.

\section{Introduction}

Vegetable oils both have important functional properties for human nutrition and act as a carrier of fat-soluble vitamins (Moreira et al., 1999). The fatty acid compositions of vegetable oils identify their nutritional properties and special areas of use for the oil (Burton et al., 2004).

Sunflower oil is one of the most important vegetable oils used in the food industry in the production of commercial products. Sunflower genotypes are separated into three main groups according to their oleic acid contents: (i) standard (traditional) sunflowers that contain 14 to $39 \%$ oleic acid (ii) mid-oleic sunflowers that contain 42 to $72 \%$ oleic acid, and (iii) high-oleic sunflowers that contain 75 to $91 \%$ oleic acid (Food and Agriculture Organization of the United Nations, 1999).

Some environmental factors, such as temperature, sunlight and precipitation, affect the growth of sunflowers differently (Kandil et al., 1990; Flagella et al., 2002; Qadir et al., 2006; Merwe et al., 2013). The most important parameter affecting plant development and fatty acid accumulation is temperature (Ritchie \& NeSmith, 1991). During seed development, temperature significantly affects the oleic acid content. Every $1{ }^{\circ} \mathrm{C}$ increase in temperature causes a $2 \%$ increase in oleic acid content (Demurin et al., 2000). Sunflower genotypes may show different characteristics under different environmental conditions (Qadir et al., 2006). Different sowing dates produce blooming and seed growth at different times, so this means the environmental conditions are different during the seed formation period and the oil synthesis (Kandil et al., 1990; Gupta et al., 1994; Flagella et al., 2002; Qadir et al., 2006;
Zheljazkov et al., 2011; Merwe et al., 2013). In particular, it is known that the fatty acid composition varies by genotype and by environmental conditions (Connor \& Sadras, 1992). Because of this, knowing how, and in which situation, oil crops differ in fatty acid composition is very significant for oil quality. For this purpose, it is possible to produce the varieties suitable for the desired oil types by cultivating them in the appropriate regions.

With the change in our consumption habits, there is an increased demand for oil which is less saturated, that is resistant to high temperatures during heat treatment and that has a resistance to oxidation for a long time. It is important to produce sunflower oil that contains low-linoleic and high-oleic acid contents to meet these needs. In order to improve the quality of the oil in the oil plants, the effects of the genotype and environment on the oil ratio and fatty acid composition must be better understood.

Various studies on the effect of the sowing date on the oil yield and fatty acid composition in standard sunflower genotypes are quite common (Unger, 1980; Kandil et al., 1990; Gupta et al., 1994; Qadir et al., 2006). However, these studies were limited to mid-oleic and high-oleic sunflower genotypes (Zheljazkov et al., 2011; Merwe et al., 2013). A similar study has not previously been carried out in Çukurova where sunflower farming has been carried out for the last 15 years and which has a special climate in terms of temperature and humidity. In addition, this study, done with sunflower genotypes that have three different levels of oleic acid content, is the first in this region. For this study, the oil ratios and fatty acid compositions for two of each standard, 
mid-oleic and high-oleic sunflower variety were compared at different sowing dates.

With the development of sunflower genotypes with different fatty acid compositions, it is also necessary to evaluate the oil ratios and fatty acid compositions in relation to their sowing date in the eastern Mediterranean region. This study attempted to determine the change in oil content and fatty acid composition depending on genotypes and sowing dates, and also the optimum sowing dates for sunflowers cultivated in the Eastern Mediterranean region.

\section{Materials and methods}

\subsection{Materials}

A total of six commercially available sunflowers, including two standard types (Sambro MR and Tunca), two mid-oleic types (Saray and 10 TR 054) and two high-oleic types (P64H34 and Oleko), were used in this research. The research was carried out at 15 days intervals (i. 15 April (SD1), ii. 30 April (SD2), iii. 15 May (SD3), iv. 30 May (SD4) in 2015 and 2016) at the Eastern Mediterranean Agricultural Research Institute experimental site ( $36^{\circ} 51^{\prime} 13^{\prime \prime} \mathrm{N}$ and $35^{\circ} 20^{\prime} 41^{\prime \prime} \mathrm{E}$ ) (Adana / Turkey) under dry conditions.

\subsection{Moisture content and oil extraction}

Before extraction, sunflower samples were cleaned of foreign materials like stems and leaves. Approximately $10 \mathrm{~g}$ of the sample from the cleaned sunflower seed was weighed on a $0.001 \mathrm{~g}$ precision scale and the humidity was determined by holding the sample at $103{ }^{\circ} \mathrm{C}$ for 3 hours (International Organization for Standardization, 2000). Subsequently, $50 \mathrm{~g}$ of the cleaned sample was taken and milled with a waring blender (Waring Commercial, USA) to a diameter of $1 \mathrm{~mm}$. Approximately $5 \mathrm{~g}$ of the sample was taken from the ground sunflower seeds and extracted with $150 \mathrm{~mL}$ of petroleum ether for 3 hours using a Soxhlet oil determination device (Gerhardt Analytical Systems, Germany) (International Organization for Standardization, 2009). At the end of the extraction, the oil ratios of the sunflower samples were determined in terms of dry matter.

\subsection{Fatty acid analysis by gas chromatography}

The extracted crude oils were then analysed by gas chromatography (GC) after the esterification. An $0.5 \mathrm{~g}$ sample of oil was transferred into a $10 \mathrm{~mL}$ capacity glass tube. Five millilitres of $n$-heptane was added into the tube. A $200 \mu \mathrm{L} 2 \mathrm{M}$ potassium hydroxide solution in methanol was added to this mixture. After mixing for 20 seconds, the upper phase was separated and analysed by gas chromatography (Turkey, 2010). The gas chromatography equipment featured a capillary column (Fused silica, $100 \mathrm{~m} \times 0.25 \mathrm{~mm} \times 0.2 \mu \mathrm{m}$ ) and a flame ionization detector (FID), (Agilent 7890A, Agilent Technologies, USA). The GC conditions used to determine fatty acid methyl ester (FAME) were as follows: (Turkey, 2010); an injection volume of $1 \mu \mathrm{L}$; a temperature program of $175^{\circ} \mathrm{C}$ for $10 \mathrm{~min}, 5^{\circ} \mathrm{C} / \mathrm{min}$ to $210{ }^{\circ} \mathrm{C}, 5^{\circ} \mathrm{C} / \mathrm{min}$ to $230^{\circ} \mathrm{C}$ and a final temperature of $230^{\circ} \mathrm{C}$ for 15 minutes; a detector temperature of $260{ }^{\circ} \mathrm{C}$; an injector

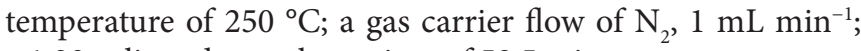
a 1:20 split and a total run time of 58.5 minutes.

\subsection{Statistical analysis}

Data were analysed statistically using the JMP 7.0 software package. The experiments were performed in three separate batches with three replications. Statistical analyses of data were carried out using a randomised split block design, and the treatment data were subjected to analysis of variance against specific levels of significance. The data were compared by the least significant difference (LSD) test, with a significance level of 0.05 .

\section{Results and discussion}

\subsection{Climatic data}

The annual climate data from the sunflower sowing dates to harvest dates during the years of the study are shown in Table 1. In both years of the study the average temperature $\left(22.8^{\circ} \mathrm{C}\right)$ was higher than the average temperature $\left(22.5^{\circ} \mathrm{C}\right)$ for many years. When we look at the average relative humidity in the vegetation period, where the mean annual average was $67.2 \%$ for many years, it was $67.6 \%$ and $69.8 \%$ in the first and second year of the study, respectively.

When we examined the amount of precipitation in the months corresponding to the vegetation period of the sunflowers, it was

Table 1. Temperature, relative humidity, rainfall and rainy days data for the cropping season and long term years.

\begin{tabular}{|c|c|c|c|c|c|c|c|c|c|c|c|c|}
\hline & \multicolumn{3}{|c|}{ Temperature $\left({ }^{\circ} \mathrm{C}\right)$} & \multicolumn{3}{|c|}{ Relative humidity (\%) } & \multicolumn{3}{|c|}{ Rainfall (mm) } & \multicolumn{3}{|c|}{ Rainy days } \\
\hline & First year & $\begin{array}{c}\text { Second } \\
\text { year }\end{array}$ & $\begin{array}{l}\text { Long } \\
\text { term } \\
\text { years }\end{array}$ & First year & $\begin{array}{c}\text { Second } \\
\text { year }\end{array}$ & $\begin{array}{l}\text { Long } \\
\text { term } \\
\text { years }\end{array}$ & First year & $\begin{array}{c}\text { Second } \\
\text { year }\end{array}$ & $\begin{array}{l}\text { Long } \\
\text { term } \\
\text { years }\end{array}$ & First year & $\begin{array}{l}\text { Second } \\
\text { year }\end{array}$ & $\begin{array}{c}\text { Long } \\
\text { term year }\end{array}$ \\
\hline March & 13.9 & 15.1 & 13.5 & 61.1 & 65.5 & 66 & 70.1 & 56.1 & 65.6 & 3 & 9 & 9.8 \\
\hline April & 18.1 & 18.3 & 17.5 & 72.0 & 69.2 & 69 & 43.2 & 18.6 & 56.3 & 11 & 7 & 9.2 \\
\hline May & 22.7 & 21.3 & 21.7 & 72.3 & 70.4 & 67 & 57.4 & 22.4 & 45.2 & 6 & 5 & 6.5 \\
\hline June & 25.3 & 24.8 & 25.6 & 65.7 & 70.5 & 66 & 0.3 & 50.0 & 19.6 & 1 & 3 & 2.9 \\
\hline July & 28.2 & 28.2 & 28.1 & 65.2 & 72.6 & 68 & 0.0 & 0.3 & 6.9 & 0 & 1 & 0.9 \\
\hline August & 28.6 & 29.1 & 28.5 & 69.0 & 70.3 & 67 & 0.0 & 0.3 & 5.6 & 0 & 1 & 0.8 \\
\hline $\begin{array}{c}\text { Mean / } \\
\text { Total }\end{array}$ & 22.8 & 22.8 & 22.5 & 67.6 & 69.8 & 67.2 & 171.0 & 147.6 & 199.2 & 21 & 26 & 30.1 \\
\hline
\end{tabular}


$171 \mathrm{~mm}$ and $147.6 \mathrm{~mm}$ in the first and second year of the study, respectively, which is below the average amount of precipitation (199.2 $\mathrm{mm}$ ) for many years. Similarly, the number of rainy days in both years ( 21 and 26 days) of the research in the vegetation period was below the average number of rainy days (30.1 days) for many years.

\subsection{Crude oil}

The crude oil ratios of the sunflower samples investigated are shown in Table 2. While the mean crude oil ratios ranged from $38.82 \%$ to $44.42 \%$, the highest crude oil ratio (44.42\%) was found in the standard type sunflower variety, Tunca. When we evaluated the crude oil ratios according to sunflower types, the highest crude oil ratio was found in standard type sunflowers with $42.57 \%$. When we evaluated the data according to sowing time, the highest crude oil ratio was determined to be $47.90 \%$ in $\mathrm{SD} 1$, for the standard type sunflower variety, Tunca. In general, the crude oil ratios were decreased for SD4 in all varieties; however, this difference was statistically significant $(p<0.05)$ in medium-oleic and high-oleic sunflowers but not significant ( $p>0.05)$ in standard sunflower varieties. While in mid-oleic and high-oleic sunflowers, crude oil ratios were generally stable for the first three sowing dates, standard type sunflowers were stable for all sowing dates.
Piva et al. (2000) and Merwe et al. (2013) reported that high temperatures during the ripening period of the sunflowers may cause low oil ratios. Reduced crude oil ratios in all types of sunflower in SD4 are due to a shorter vegetation period than other planting times because of high temperature and low rainfall during the vegetation process and the seed filling stage. The fat ratios we obtained from this research are in good agreement with the research results of Kandil et al. (1990), Gupta et al. (1994), Qadir et al. (2006), Zheljazkov et al. (2011) and Merwe et al. (2013).

\subsection{Oleic acid}

The average percentages of oleic acid obtained in the study were $60.08 \%, 74.35 \%$ and $88.01 \%$ in standard, mid-oleic and high-oleic sunflower varieties (Table 3 ). When the variation in oleic acid ratios were examined according to the sowing date, it was seen that the sowing date in both of the high-oleic sunflowers, and the Saray variety of the mid-oleic sunflowers, did not affect the oleic acid ratio ( $p>0.05)$. It was observed that in the 10 TR 55 variety of mid-oleic sunflowers, and in both standard types of sunflower, the oleic acid ratios reached the highest level in SD2. There was a significant statistical difference between the oleic acid ratios of SD1 and SD2 in these varieties ( $p<0.05)$.

Table 2. Oil contents of sunflower types at four sowing dates.

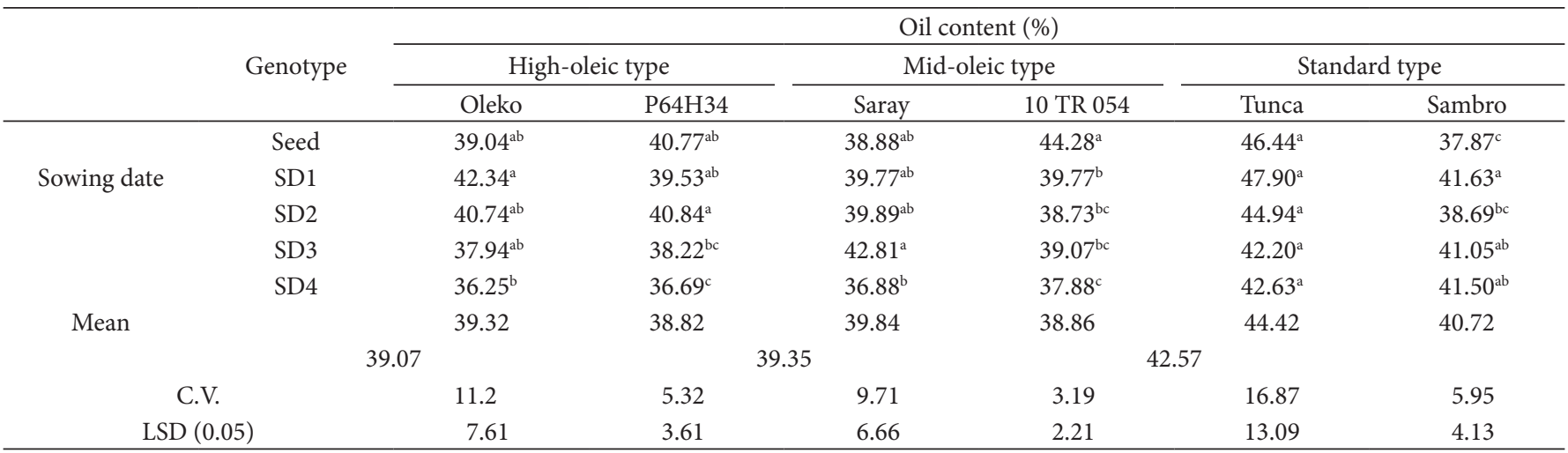

$\mathrm{CV}=$ Coefficient of Variation; LSD $=$ Least significant difference. Values with different letters within a column are significantly different $(\mathrm{P}<0.05)$.

Table 3. Oleic acid contents of sunflower types at four sowing dates.

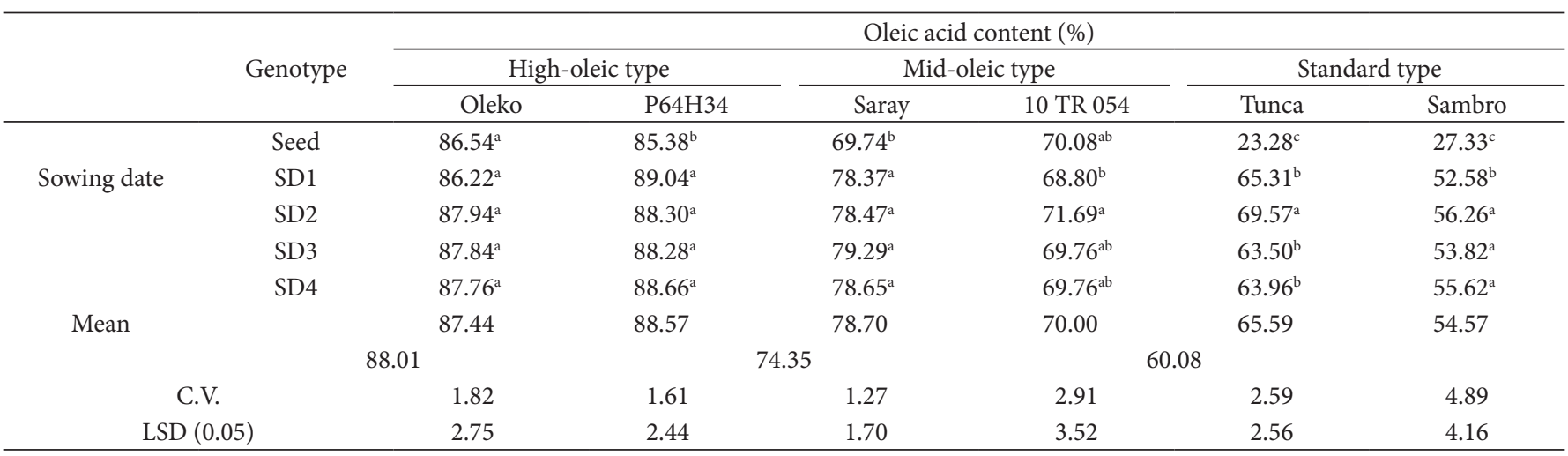

$\mathrm{CV}=$ Coefficient of Variation; LSD $=$ Least significant difference. Values with different letters within a column are significantly different $(\mathrm{P}<0.05)$. 
The amount of oleic acid in the standard type sunflower was found to be about twice as high as the oleic acid content of the seeds. This is thought to be because the climate in which the seeds are grown is cooler than the climate in which we conducted our research. Thus, the oleic acid ratios of Saray, which is a mid-oleic sunflower variety, at all sowing dates showed the oil properties of a high-oleic sunflower according to the classification in Codex Alimentarius (Food and Agriculture Organization of the United Nations, 1999). Standard type sunflowers showed the oil properties of mid-oleic sunflowers according to the same classification.

Piva et al. (2000), Echarte et al. (2010) and Merwe et al. (2013) reported that the oleic acid concentrations were higher in warmer and drier environmental conditions. While the oleic acid ratios of high-oleic and mid-oleic sunflowers were similar to the previous studies done by Izquierdo et al. (2002), Flagella et al. (2002) and Zheljazkov et al. (2011), they were found to be more than the results in the study done by Merwe et al. (2013). The oleic acid ratios of standard sunflowers were higher than those of previous studies (Unger, 1980; Kandil et al., 1990; Izquierdo et al., 2009; Merwe et al., 2013; Alberio et al., 2016). This situation is thought to be caused entirely by the climate and environmental characteristics of the region.

\subsection{Linoleic acid}

Table 4 shows the linoleic acid ratios of sunflower oils. Linoleic acid ratio averages were determined to be $29.56 \%, 15.82 \%$ and $3.28 \%$ in standard, mid-oleic and high-oleic sunflower varieties, respectively. Because of the negative correlation between oleic acid and linoleic acid, as oleic acid increases, linoleic acid decreases and vice versa (Lajara et al., 1990). A similar situation was found in this research. The linoleic acid ratios were reduced to their lowest level in SD2, which has the highest oleic acid content for both standard and mid-oleic sunflowers. There is a statistically significant difference in the linoleic acid ratios of these varieties in SD1 and SD2 $(\mathrm{p}<0.05)$.

While linoleic acid ratios of high-oleic and mid-oleic sunflowers were similar to the previous studies by Izquierdo et al. (2002), Izquierdo \& Aguirrezabal (2008), Alberio et al. (2016), they were found to be below the results of the studies done by
Flagella et al. (2002) and Merwe et al. (2013). The linoleic acid content of standard sunflowers was found to be lower than most of the previous studies (Unger, 1980; Kandil et al., 1990; Izquierdo \& Aguirrezabal, 2008; Merwe et al., 2013; Alberio et al., 2016). In addition, standard varieties of sunflowers showed the characteristics of mid-oleic sunflowers in terms of linoleic acid content according to the Codex Alimentarius (Food and Agriculture Organization of the United Nations, 1999), as in the case of the oleic acid ratios for all sowing dates. Saray, a mid-oleic sunflower variety, showed the characteristics of high-oleic sunflowers.

\subsection{Palmitic acid}

The mean palmitic acid ratios of the sunflower oils in the study are shown in Table 5. The palmitic acid ratios were $4.68 \%$, $4.51 \%$ and $3.85 \%$ in standard, mid-oleic and high-oleic sunflower varieties, respectively.

The increase in temperature during ripening reduces the palmitic acid ratio in standard type sunflowers (Qadir et al., 2006). In this study, when we evaluated the palmitic acid ratios at the sowing dates and seed, we found lower palmitic acid ratios in standard type sunflowers than seeds for all sowing dates. No significant difference was observed during sowing dates. In mid-oleic and high-oleic sunflowers, the highest palmitic acid ratios were found in SD4 ( $\mathrm{p}<0.05)$. This case indicates that the negative correlation between temperature and palmitic acid ratios expressed in standard type sunflowers (Qadir et al., 2006) may not occur in mid-oleic and high-oleic sunflowers. The palmitic acid ratios of high-oleic and mid-oleic sunflowers are in good agreement with Izquierdo et al. (2002), Flagella et al. (2002), Izquierdo \& Aguirrezabal (2008) and Grunvald et al. (2013). The palmitic acid ratios of the standard type sunflower were found to be lower than the studies done by Kandil et al. (1990), Izquierdo et al. (2002, 2009), Qadir et al. (2006) and Grunvald et al. (2013).

\subsection{Stearic acid}

The mean stearic acid ratios found in the study were $3.38 \%$, $3.21 \%$ and $2.68 \%$ in standard, mid-oleic and high-oleic sunflower varieties, respectively (Table 6).

Table 4. Linoleic acid contents of sunflower types at four sowing dates.

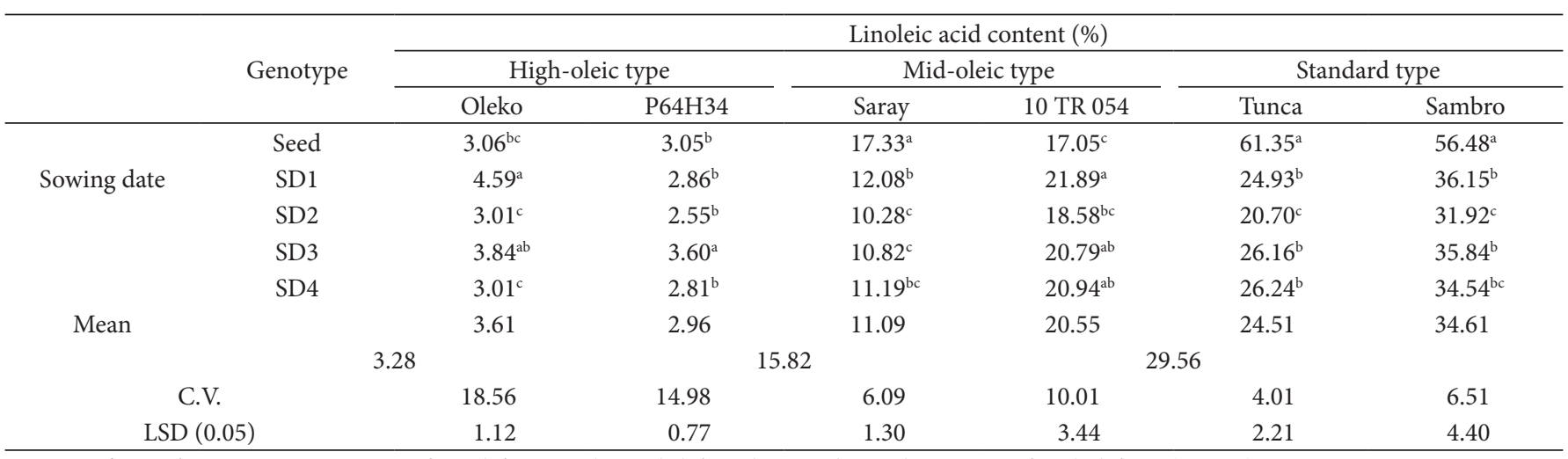

$\mathrm{CV}=$ Coefficient of Variation; LSD = Least significant difference. Values with different letters within a column are significantly different $(\mathrm{P}<0.05)$. 
Table 5. Palmitic acid contents of sunflower types at four sowing dates.

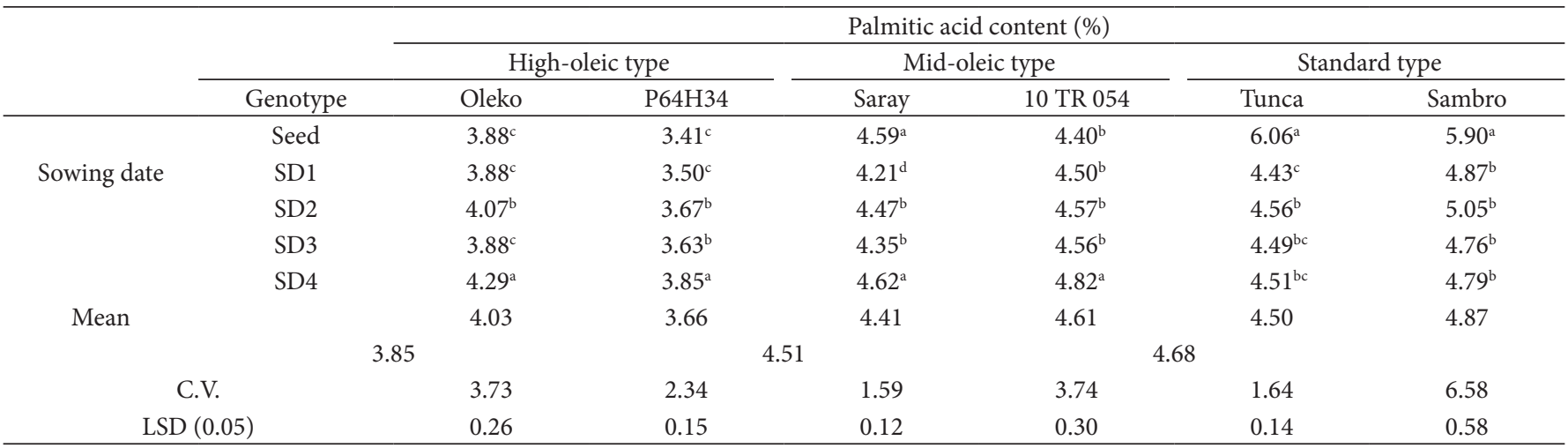

$\mathrm{CV}=$ Coefficient of Variation; LSD = Least significant difference. Values with different letters within a column are significantly different $(\mathrm{P}<0.05)$.

Table 6. Stearic acid contents of sunflower types at four sowing dates.

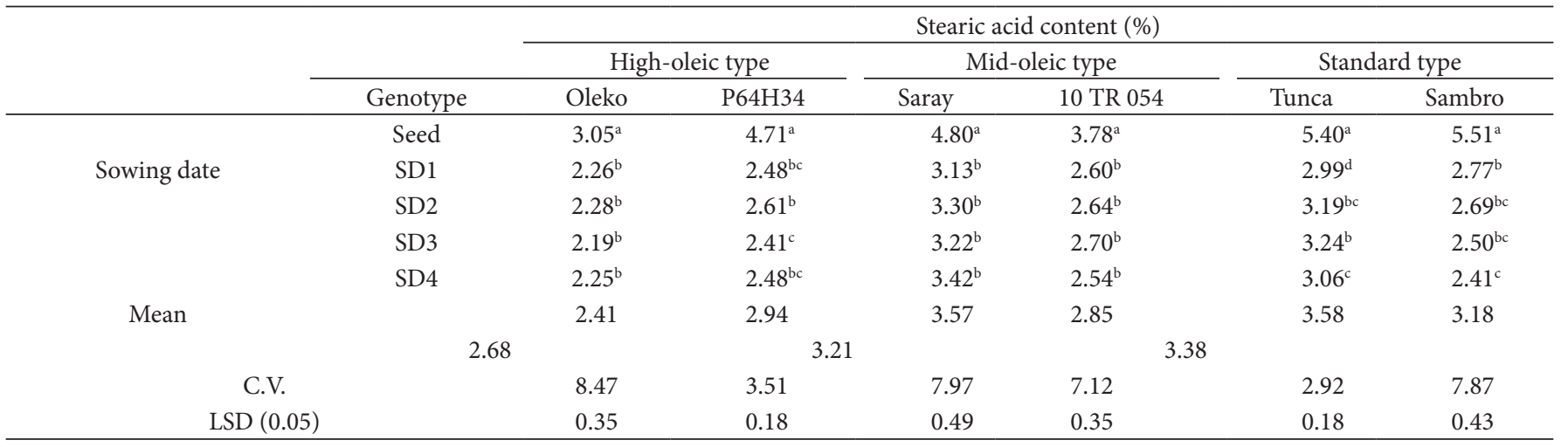

$\mathrm{CV}=$ Coefficient of Variation; LSD = Least significant difference. Values with different letters within a column are significantly different $(\mathrm{P}<0.05)$.

When we evaluated the stearic acid ratios according to the sowing dates, none of the sunflower types showed any distinct difference. However, when compared to the stearic acid ratios in seeds, the stearic acid ratios in all types of sunflower were significantly reduced $(p<0.05)$. When the seeds were thought to have been grown in cooler regions, this case can be thought to be parallel with the results of Qadir et al., (2006).

While stearic acid ratios of all types of sunflowers were similar to the previous studies done by Kandil et al. (1990), Qadir et al. (2006), Izquierdo \& Aguirrezabal (2008), they were found to be below the results of the studies done by Izquierdo et al. (2002), Flagella et al. (2002), Izquierdo et al. (2009) and Grunvald et al. (2013).

\section{Conclusions}

Sunflower oil compositions and fatty acid compositions vary with the environment, depending on the genotype and genotype association. Climate conditions such as high temperature and low rainfall during the seed filling stage caused a decrease in the oil ratio and an increase in oleic acid in the oil. As the sowing date gets later and the temperature increases during maturation, the oil percentage in the sunflowers decreased in general. In addition, oleic acid levels did not increase further in standard sunflower seeds after SD2 (30 April). The oleic acid ratios of mid-oleic and high-oleic sunflowers were generally stable even when the sowing dates varied. For all of these reasons, it is thought that it would be more appropriate to sow the sunflowers between SD1 and SD2 (15 April to 30 April). In addition to these results, the oleic acid content of oils obtained from sunflowers grown in the Çukurova region may be twice or more than that of standard type sunflowers. As a result of this, the oils obtained from standard and mid-oleic type sunflowers show the oil properties of mid-oleic and high-oleic sunflowers, respectively. This property of the region appears to be an advantage in the vegetable oil market due to the increase in requirements for high oleic acid contents that produce a resistance to oxidation and a resistance to high temperatures.

\section{Acknowledgements}

This research was financially supported by Ministry of Food Agriculture and Livestock General Directorate of Agricultural Research and Policy as a part of a research project (TAGEM/HSGYAD/13/A05/P01/26). I'm grateful laboratory assistant Hakan Erdoğan.

\section{References}

Alberio, C., Izquierdo, N. G., Galella, T., Zuil, S., Reid, R., Zambelli, A., \& Aguirrezábal, L. A. N. (2016). A new sunflower high oleic mutation confers stable oil grain fatty acid composition across 
environments. European Journal of Agronomy, 73, 25-33. http:// dx.doi.org/10.1016/j.eja.2015.10.003.

Burton, J. W., Miller, J. F., Vick, B. A., Scarth, R., \& Holbrook, C. C. (2004). Altering fatty acid composition in oil seed crops. Advances in Agronomy, 84, 273-306. http://dx.doi.org/10.1016/S00652113(04)84006-9.

Connor, D. J., \& Sadras, V. A. (1992). Physiology of yield expression in sunflower. Field Crops Research, 30(3-4), 333-389. http://dx.doi. org/10.1016/0378-4290(92)90006-U.

Demurin, Y., Skoric, D., Veresbaranji, I., \& Jocic, S. (2000). Inheritance of increased oleic acid content in sunflower seed oil. Helia, 23, 87-92.

Echarte, M. M., Angeloni, P., Jaimes, F., Tognetti, J., Izquierdo, N. G., Valentinuz, O., \& Aguirrezabal, L. A. N. (2010). Night temperature and intercepted solar radiation additively contribute to oleic acid percentage in sunflower oil. Field Crops Research, 119(1), 27-35. http://dx.doi.org/10.1016/j.fcr.2010.06.011.

Flagella, Z., Rotunno, T., Tarantino, E., Caterina, R., \& Caro, A. (2002). Changes in seed yield and oil fatty acid composition of high oleic sunflower (Helianthus annuus L.) hybrids in relation to the sowing date and the water regime. European Journal of Agronomy, 17(3), 221-230. http://dx.doi.org/10.1016/S1161-0301(02)00012-6.

Food and Agriculture Organization of the United Nations - FAO. (1999). Codex-stan 210-1999: standard for named vegetable oils. Rome: FAO.

Grunvald, A. K., Carvalho, C. G. P., Leite, R. S., Mandarino, J. M. G., Andrade, C. A. B., Amabile, R. F., \& Godinho, V. P. G. (2013). Influence of temperature on the fatty acid composition of the oil from sunflower genotypes grown in tropical regions. Journal of the American Oil Chemists' Society, 90(4), 545-553. http://dx.doi. org/10.1007/s11746-012-2188-6.

Gupta, S., Subrahmanyam, D., \& Rathore, V. S. (1994). Influence of sowing dates on yield and oil quality in sunflower. Journal Agronomy \& Crop Science, 172(2), 137-144. http://dx.doi.org/10.1111/j.1439037X.1994.tb00539.x.

International Organization for Standardization - ISO. (2000). ISO 665: oilseeds: determination of moisture and volatile matter content. Geneva: ISO.

International Organization for Standardization - ISO. (2009). ISO 659: oilseeds: determination of oil content. Geneva: ISO.

Izquierdo, N. G., Aguirrezabal, L. A. N., Andrade, F. H., Geroudet, C., Valentinuz, O., \& Pereyra Iraola, M. (2009). Intercepted solar radiation affects oil fatty acid composition in crop species. Field Crops Research, 114(1), 66-74. http://dx.doi.org/10.1016/j.fcr.2009.07.007.
Izquierdo, N. G., Aguirrezabal, L. A. N., Andrade, F., \& Pereyra, V. (2002). Night temperature affects fatty acid composition in sunflower oil depending on the hybrid and the phenological stage. Field Crops Research, 77(2-3), 115-126. http://dx.doi.org/10.1016/ S0378-4290(02)00060-6.

Izquierdo, N., \& Aguirrezabal, L. (2008). Genetic variability in the response of fatty acid composition to minimum night temperature during grain filling in sunflower. Field Crops Research, 106(2), 116125. http://dx.doi.org/10.1016/j.fcr.2007.10.016.

Kandil, A., Ibrahim, A. F., Marquard, R., \& Taha, R. S. (1990). Response of some quality traits of sunflower seeds and oil to different environments. Journal Agronomy \& Crop Science, 164(4), 224-230. http://dx.doi.org/10.1111/j.1439-037X.1990.tb00811.x.

Lajara, J., Diaz, U., \& Quidiello, R. (1990). Definite influence of location and climatic conditions on the fatty acid composition on sunflower seed oil. Journal of the American Oil Chemists' Society, 67(10), 618623. http://dx.doi.org/10.1007/BF02540410.

Merwe, R. V. D., Labuschagne, M. T., Herselman, L., \& Hugo, A. (2013). Stability of seed oil quality traits in high and mid-oleic acid sunflower hybrids. Euphytica, 193, 157-168.

Moreira, R. G., Castell-Perez, M. E., \& Barrufet, M. A. (1999). Deep-fat frying fundamentals and applications. Gaithersburg: Aspen Publication.

Piva, G., Bouniols, A., \& Mondies, M. (2000). Effect of cultural conditions on yield, oil content and fatty acid composition of sunflower kernel. In Proceedings of the 15th International Sunflower Conference (pp. A61-A66). Toulouse: ISA.

Qadir, G., Ahmad, S., Hassan, F. U., \& Cheema, M. A. (2006). Oil and fatty acid accumulation in sunflower as influenced by temperature variation. Pakistan Journal of Botany, 38(4), 1137-1147.

Ritchie, J.T., \& NeSmith, D. S. (1991). Temperature and crop development. Agronomy Journal, 31, 5-29.

Turkey. (2010). Methods of sampling and analysis of olive oil and oliveresidue oil (Notification $n^{\circ}$. 2010/36). Official Gazette.

Unger, P. (1980). Planting date effects on growth, yield and oil of irrigates sunflower. Agronomy Journal, 72(6), 914-916. http://dx.doi. org/10.2134/agronj1980.00021962007200060012x.

Zheljazkov, V. D., Vick, B. A., Baldwin, B. S., Buehring, N., Coker, C., Astatkie, T., \& Johnson, B. (2011). Oil productivity and composition of sunflower as a function of hybrid and planting date. Industrial Crops and Products, 33(2), 537-543. http://dx.doi.org/10.1016/j. indcrop.2010.11.004. 